\title{
Subacute bacterial endocarditis in a patient with ankylosing spondylitis
}

\author{
RICHARD A HOPPMANN, ${ }^{1}$ CHRISTOPHER M WISE, \\ VENKATA R CHALLA, ${ }^{2}$ AND JAMES E PEACOCK
}

From the Departments of ${ }^{\prime}$ Medicine and ${ }^{2}$ Pathology, Bowman Gray School of Medicine of Wake Forest University

SUMmARY A 57 year old white man with aortic insufficiency and previously undiagnosed ankylosing spondylitis, who developed subacute bacterial endocarditis (SBE), is described. Emergency aortic valve replacement was necessary, and the aortic valve pathology showed diffusely fibrosed and thickened valve leaflets with bacterial vegetations. This is the first recorded case of SBE in ankylosing spondylitis.

Mallory is generally credited with first reporting the association between ankylosing spondylitis and aortic insufficiency in 1936. ${ }^{\prime}$ Graham and Smythe in 1958 reported on 519 patients with ankylosing spondylitis, $10 \%$ of whom had aortic insufficiency. Numerous other reports have followed recording the association of ankylosing spondylitis and aortic insufficiency, with prevalences of aortic insufficiency up to Graham and Smythe's orginal figure of $10 \%$. The aortic insufficiency of ankylosing spondylitis results from fibrous shortening and thickening of the aortic valve leaflets and dilatation of the aortic root. Extension of the fibrosis into the ventricular septum and the conduction system gives rise to the various forms of heart block seen in ankylosing spondylitis. ${ }^{3}$

In the light of the prevalence of associated valvular abnormalities in patients with ankylosing spondylitis one would expect SBE to be occasionally encountered, but an extensive review of published work has failed to show any well recorded cases of SBE complicating ankylosing spondylitis. There exist only four incomplete cases, in which neither the diagnosis of ankylosing spondylitis nor SBE is substantiated. ${ }^{4-6}$ The following case represents the first documented case of SBE in ankylosing spondylitis.

Accepted for publication 26 October 1987.

Correspondence to Dr Richard A Hoppmann, Rheumatology Section, East Carolina University School of Medicine, Greenville, NC 27858-4354, USA.

\section{Case report}

A 57 year old white man presented to his local emergency room on 2 February 1986 with acute onset of left eye blindness and an erythrocyte sedimentation rate of $60 \mathrm{~mm} / \mathrm{h}$. He was given 100 $\mathrm{mg}$ of prednisone and transferred to our faculty. There was no history of prior visual changes, headaches, stiffness, or jaw claudication. He denied fever, weight loss, myalgias, or arthritis, except for occasional low back pain.

His past medical history included peptic ulcer disease, prostatitis, mild aortic insufficiency, and placement of an atrioventricular sequential pacemaker for syncopal episodes secondary to Wenckebach arrhythmia in December 1981.

Physical examination was remarkable for an infected left conjunctiva. Fundoscopic examination of the left eye showed a pale retina, and the eye was blind. Temporal arteries were non-tender. Heart examination showed a $2 / 6$ systolic murmur and a $2 / 6$ diastolic murmur, both heard best in the aortic region and apparently unchanged from previous evaluations. There were no significant skin lesions. Laboratory investigation showed haemoglobin 150 $\mathrm{g} / \mathrm{l}$, white blood cell count $10 \cdot 7 \times 10^{9} / 1$, and erythrocyte sedimentation rate $40 \mathrm{~mm} / \mathrm{h}$.

He was admitted to the hospital and given $60 \mathrm{mg}$ of prednisone a day. A right temporal artery biopsy was normal. Doppler studies of the carotid arteries showed minimum plaque formation without signifi- 
cant stenotic flow. Two dimensional echocardiography showed thickening of the aortic valve without evidence of vegetations. A rheumatoid factor (latex and sheep cell agglutination test (SCAT)) and antinuclear antibody (ANA) tests were negative. Prednisone was discontinued, and the patient was discharged with a diagnosis of left retinal artery occlusion, probably secondary to an embolic event.

He was readmitted on 11 March 1986 with a two day history of intermittent left shoulder and arm pain associated with diaphoresis. Physical examination was unchanged from the previous stay in hospital. Electrocardiogram showed totally paced rhythm and chest $x$ ray revealed mild cardiomegaly and increased vascular markings. Laboratory studies were as follows: haemoglobin $115 \mathrm{~g} / \mathrm{l}$, white blood cell count $11.6 \times 10^{9} / 1$, normal urine analysis, normal blood chemistries, erythrocyte sedimentation rate $79 \mathrm{~mm} / \mathrm{h}$, and creatine phosphokinase $91 \mathrm{U}$.
Because of an increase in the creatine phospho- $-\bar{O}$. kinase to $231 \mathrm{U}$ with a $15 \%$ MB band the patient? underwent coronary arteriography, which showed $\overrightarrow{\vec{S}^{*}}$ no significant coronary artery disease, $4+$ aortie insufficiency, and mild aortic valve calcification $\frac{}{0}$ Upper gastrointestinal series, barium enema, anden. sigmoidoscopy were normal. Serum iron and totak iron binding capacity were consistent with chronic disease. Four sets of blood cultures were initiallye negative. Serum protein electrophoresis did noto show a monoclonal protein. Left temporal artery $\vec{\omega}_{\vec{H}}$ biospy was normal.

Further interrogation revealed back pain that wasov worse with inactivity. Schober test was positive for? decreased lumbar flexion. Sacroiliac joint filmș showed fusion of the sacroiliac joints and synor desmophyte formation (Fig. 1). HLA-B27 waș positive. He was given naproxen with some imo provement and discharged with a diagnosis of

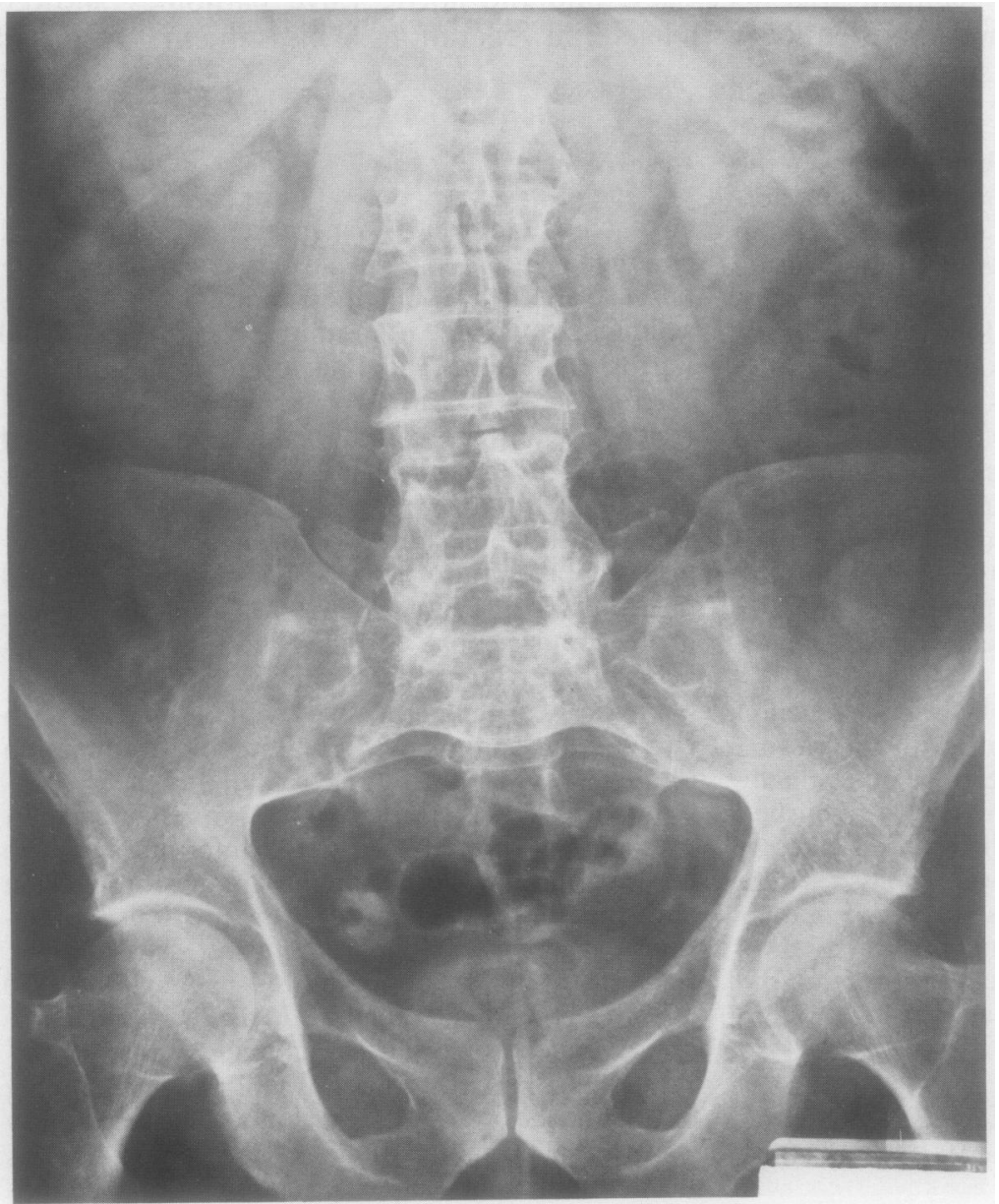

Fig. 1 Anteroposterior radiograph showing fusion of the sacroiliac joints bilaterally and syndesmophyte formation. 
ankylosing spondylitis but was readmitted three days later with left shoulder and neck pain, myalgias, fever to $38.9^{\circ} \mathrm{C}$, and dyspnoea on exertion. Haemoglobin was $91 \mathrm{~g} / \mathrm{l}$, white blood cell count $8 \cdot 2 \times 10^{9} / 1$, and the erythrocyte sedimentation rate 72 $\mathrm{mm} / \mathrm{h}$. It was noted that one blood culture drawn on the day of his previous discharge was now growing Staphylococcus epidermidis. Repeat two dimensional echocardiogram showed a large vegetation on the aortic valve. Rheumatoid factor was now positive with a latex test titre of $1 / 640$ and a SCAT of $1 / 128$. An ANA test was positive at $1 / 100$ with a homogeneous pattern.
He was given intravenous vancomycin and gentamycin for presumed infectious endocarditis. After two weeks of treatment he experienced acute cardiac decompensation secondary to progressive aortic insufficiency necessitating emergency aortic valve replacement. Culture of valve tissue was negative.

Pathological examination of the aortic valve showed fibrosed and thickened leaflets with vegetations containing clusters of Gram positive cocci (Figs 2 and 3). Antibiotics were continued for a further three weeks. He was discharged and two weeks later had resumed his normal daily activities.
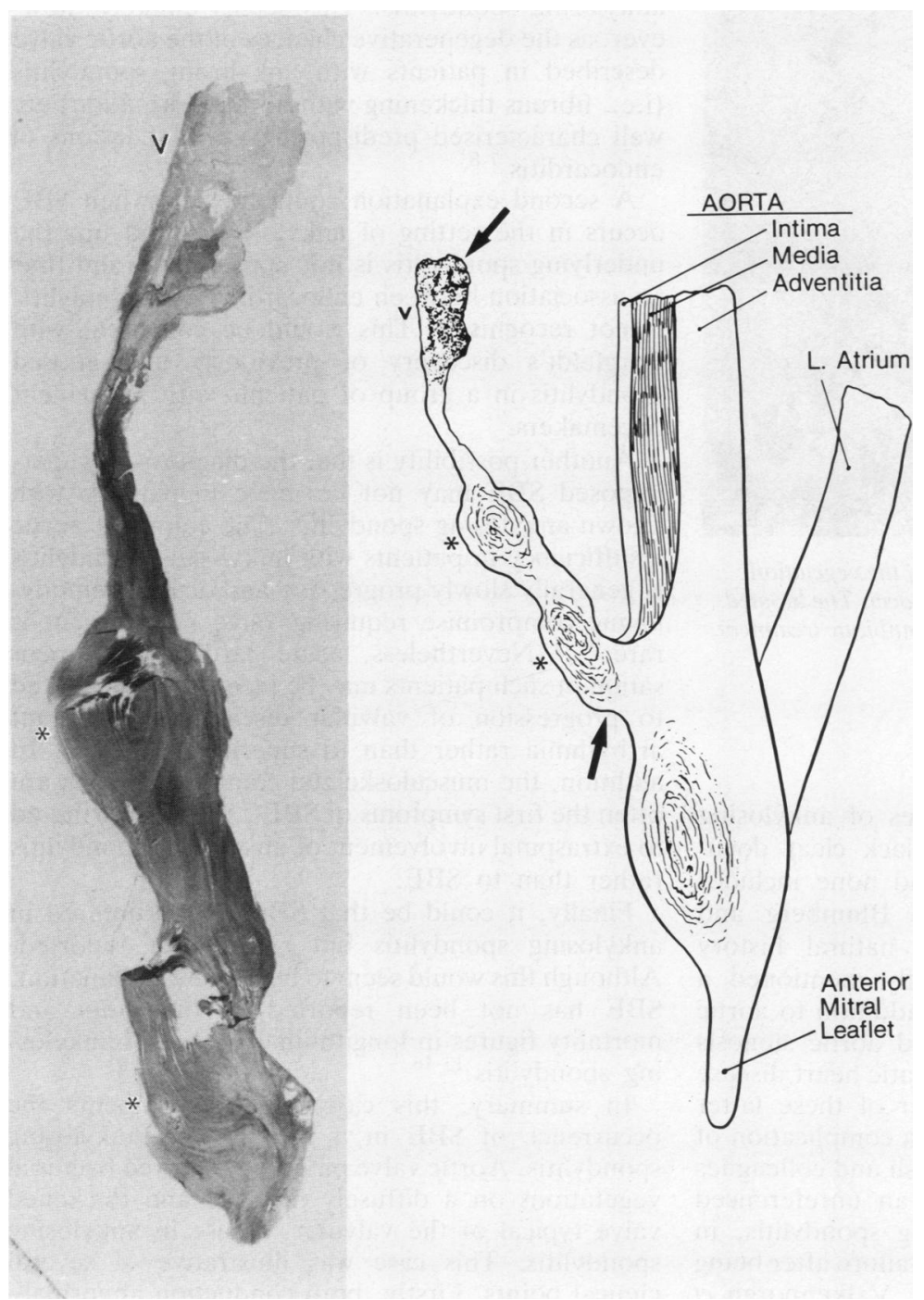

Fig. 2 On the left is a low power photomicrograph of one of the aortic leaflets and on the right $a$ diagrammatic illustration of the changes in the aortic valve in ankylosing spondylitis (modified from Bulkley $B$ H and Roberts $W C^{3}$ ). The diagram shows the fibrous thickening in the aortic adventitia extending into the mitral ring and into the aortic leaflet. It has been modified to include the site of the vegetation (V). The part of the diagram between the arrows represents the actual tissue specimen at left. Note the two hyalinised nodules $\left({ }^{*}\right)$ along the valve leaflet and the distally located vegetation $(V)$ in the tissue specimen corresponding to the same structures in the diagram. 


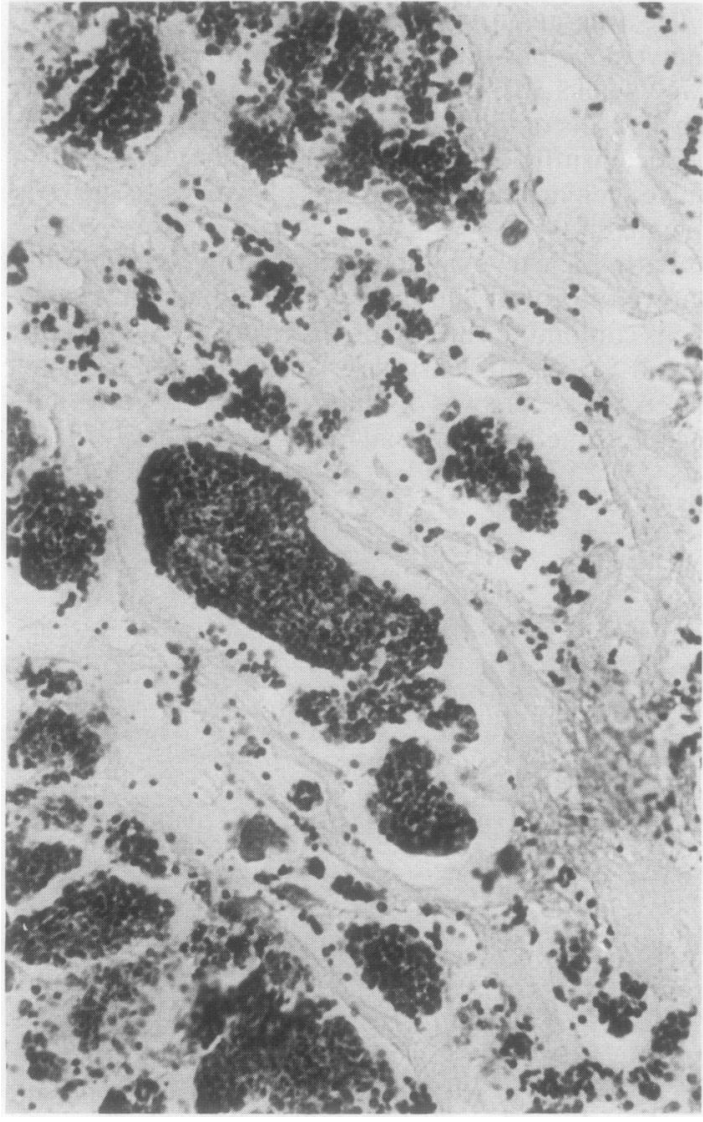

Fig. 3 High power photomicrograph of the vegetation shows numerous colonies of very large cocci. The bloated appearance of the cocci is attributed to antibiotic treatment. (Gram stain).

\section{Discussion}

The four previously reported cases of ankylosing spondylitis complicated by SBE lack clear documentation of either diagnosis, and none includes aortic valve pathology. In 1956 Blumberg and Ragan, while reporting on the natural history of 'rheumatoid spondylitis', briefly mentioned a patient who developed SBE. ${ }^{4}$ In addition to aortic insufficiency, this patient also had aortic stenosis and mitral stenosis, making rheumatic heart disease a more likely diagnosis as neither of these latter valvular lesions are recognised as a complication of ankylosing spondylitis. In 1975 Cosh and colleagues mentioned a case of SBE from an unreferenced series of patients with ankylosing spondylitis, in which one patient died from renal failure after being treated for bacterial endocarditis. ${ }^{5}$ Valkenborgh $e t$ $a l$, in 1976, presented 25 patients with various forms of inflammatory arthritis and heart disease. ${ }^{6}$ Two of ${ }^{\text {? }}$. these may have represented SBE in patients with $\overrightarrow{\vec{F}}$ ankylosing spondylitis, but they were not reported in sufficient detail to be certain of the diagnosis. $\frac{}{0}$ Thus the present case represents the first $\overline{\bar{\omega}}$ documented case of SBE in a patient with ankylos- $\mathbb{D}$ ing spondylitis. The underlying aortic valve pathology with fibrous thickening throughout the leaflet ${ }^{\text {s }}$ and fibrous nodule formation is characteristic of that $\vec{\circ}$ reported in ankylosing spondylitis. ${ }^{3}$

There are several explanations why SBE has not $\stackrel{\vec{\omega}}{\mathscr{\omega}}$ been reported in association with ankylosing spondylitis. One possibility would be that SBE truly is a rare complication of the valvular disease seen in ankylosing spondylitis. This seems unlikely, how- or ever, as the degenerative changes of the aortic valve $\overrightarrow{\mathrm{c}}$ described in patients with ankylosing spondylitiso (i.e., fibrous thickening with nodule formation) are well characterised predisposing valvular lesions of $\bar{z}$ endocarditis. ${ }^{7} 8$

A second explanation could be that when SBE occurs in the setting of ankylosing spondylitis the $\propto$ underlying spondylitis is not appreciated, and thus an association between endocarditis and spondylitis is not recognised. This would be consistent with Bergfeldt's discovery of previously undiagnosed spondylitis in a group of patients with permanent $\stackrel{0}{\circ}$ pacemakers. $^{9}$

Another possibility is that the diagnosis of super- $\overrightarrow{\overrightarrow{0}}$ imposed SBE may not be made in patients with 3 known ankylosing spondylitis. The course of aortic insufficiency in patients with ankylosing spondylitis? is generally slowly progressive and acute haemodynamic compromise requiring valve replacement is $\stackrel{0}{\circ}$ rare. ${ }^{10} 11$ Nevertheless, acute cardiac decompensation in such patients may be incorrectly attributed to progression of valvular disease or malignant $\stackrel{3}{3}$ arrhythmia rather than to superimposed SBE. In addition, the musculoskeletal complaints which are often the first symptoms of $\mathrm{SBE}^{12}$ may be attributed $\frac{D}{O}$ to extraspinal involvement of ankylosing spondylitis rather than to SBE.

Finally, it could be that SBE is encountered in ankylosing spondylitis but simply not reported. O Although this would seem to be a likely explanation, $\omega$ SBE has not been reported in morbidity and mortality figures in longitudinal studies of ankylosing spondylitis. ${ }^{13-16}$

In summary, this case report documents the $\stackrel{\mathscr{C}}{?}$ occurrence of SBE in a patient with ankylosing ${ }^{\circ}$ spondylitis. Aortic valve pathology showed bacterial $\underset{\mathbb{D}}{\circ}$ vegetations on a diffusely fibrosed and thickened $\stackrel{?}{P}$ valve typical of the valvular disease in ankylosing $\stackrel{\mathbb{Q}}{\square}$ spondylitis. This case was illustrative of several clinical points. Firstly, both conduction abnormali- 8 
ties and valvular disease occur in patients with previously undiagnosed ankylosing spondylitis. Secondly, if patients have ankylosing spondylitis and new musculoskeletal complaints, especially in the setting of systemic manifestations or acute valvular decompensation, this should alert the physician to the possibility of SBE. Thirdly, the value of serial echocardiography in diagnosing SBE was shown. Finally, valvular replacement can be successfully performed in the setting of SBE in ankylosing spondylitis.

\section{References}

1 Mallory T B. Case records of the Massachusetts General Hospital. $N$ Engl J Med 1936; 214: 690-8.

2 Graham D C, Smythe H A. The carditis and aortitis of ankylosing spondylitis. Bull Rheum Dis 1958; 9: 171-4.

3 Bulkley B H, Roberts W C. Ankylosing spondylitis and aortic regurgitation. Description of the characteristic cardiovascular lesion from study of eight necropsy patients. Circulation 1973; 18: $1014-27$.

4 Blumberg B, Ragan C. The natural history of rheumatoid spondylitis. Medicine (Baltimore) 1956; 35: 1-31.

5 Cosh J A, Gerber N, Barritt D W, Jayson M I V. Cardiac lesions in Reiter's syndrome and ankylosing spondylitis. Ann Rheum Dis 1975; 34: 195.

6 Valkenborgh P, Dequeker J, Gielen F, DeGeest H. Arthritis and heart lesions: a study of 25 cases with pericarditis or valvular lesions associated to inflammatory joint disease. Acta Cardiol (Brux) 1976; 4: 269-76.

7 Kayc D. Infective endocarditis. Baltimore: University Park Press, 1976: 6-8.

8 Scheld W M, Sande M A. Endocarditis and endovascular infections. In: Mandell G L. Douglas Jr R G, Bennett J E. eds. Principles and practice of infectious diseases. 2nd cd. New York: Wiley, 1985: 504-30.

9 Bergfeldt L. HLA B27-associated rheumatic discase with severe cardiac bradyarrhythmias. Clinical features in 223 men with permanent pacemakers. Am J Med 1983; 75: 210-5.

10 Demoulin J C, Lespagnard J, Bertholet M, Soumagne D. Acute fulminant aortic regurgitation in ankylosing spondylitis. $A m$ Heart J 1983; 105: 859-61.

11 Stewart S R. Robbins D L. Castles J J. Acute fulminant aortic and mitral insufficiency in ankylosing spondylitis. $N$ Engl J Med 1978; 299: 1448-9.

12 Churchill M A Jr, Geraci J E. Hunder G G. Musculoskeletal manifestations of bacterial endocarditis. Ann Intern Med 1977; 87: 754-9.

13 Lehtinen K. 76 patients with ankylosing spondylitis seen after 30 years of disease. Scand J Rheumatol 1983; 12: 5-11.

14 Carette S, Graham D, Little H, Rubenstein J, Rosen P. The natural disease course of ankylosing spondylitis. Arthritis Rheum 1983; 26: 186-90.

15 Hart F D, Maclagan N F. Ankylosing spondylitis: a review of 184 cases. Ann Rheum Dis 1955: 14: 77-82.

16 Wilkinson M. Bywaters E G L. Clinical features and course of ankylosing spondylitis: as seen in a follow-up of 222 hospital referred cases. Ann Rheum Dis 1958; 17: 209-28. 